\title{
Towards Advanced Fusion Gyrotrons: 2018 Update on Activities within EUROfusion
}

\author{
John Jelonnek ${ }^{1,2 *}$, Gaetano Aiello ${ }^{3}$, Stefano Alberti ${ }^{4}$, Konstantinos Avramidis ${ }^{1}$, Alex Bruschi ${ }^{5}$, Ioannis Chelis $^{6}$ \\ Thomas Franke ${ }^{7,8}$, Gerd Gantenbein ${ }^{1}$, Saul Garavaglia ${ }^{5}$, Gustavo Granucci ${ }^{5}$, Giovanni Grossetti ${ }^{3}$, Stefan Illy $^{1}$, \\ Zisis Ioannidis ${ }^{1}$, Jianbo Jin ${ }^{1}$, Parth Kalaria ${ }^{1}$, George Latsas ${ }^{6}$, Ioannis Pagonakis ${ }^{1}$, Dimitrios Peponis ${ }^{6}$, \\ Tomasz Rzesnicki ${ }^{1}$, Sebastian Ruess ${ }^{1,2}$, Tobias Ruess ${ }^{1}$, Theo Scherer ${ }^{3}$, Martin Schmid ${ }^{1}$, Dirk Strauss ${ }^{3}$, \\ Chuanren $\mathrm{Wu}^{1}$, Manfred Thumm ${ }^{1,2}$, Ioannis Tigelis ${ }^{6}$, Minh Quang Tran ${ }^{4}$, Fabian Wilde ${ }^{1,9}$, Andy Zein ${ }^{1}$ \\ ${ }^{1} \mathrm{IHM},{ }^{2} \mathrm{IHE},{ }^{3} \mathrm{IAM}-\mathrm{AWP}$, Karlsruhe Institute of Technology (KIT), D-76131 Karlsruhe, Germany, \\ ${ }^{4}$ Swiss Plasma Center (SPC), EPFL, CH-1015 Lausanne, Switzerland, \\ ${ }^{5}$ Institute of Plasma Physics "P.Caldirola", National Research Council of Italy, Milan, Italy, \\ ${ }^{6}$ National and Kapodistrian University of Athens, Faculty of Physics, Zografou, GR-157 84, Athens, Greece, \\ ${ }^{7}$ EUROfusion Consortium, D-85748 Garching, Germany, \\ ${ }^{8}$ Max-Planck-Institut für Plasmaphysik, D-85748 Garching, Germany, \\ ${ }^{9}$ Max-Planck-Institut für Plasmaphysik, Teilinstitut Greifswald, D-17491 Greifswald, Germany
}

\begin{abstract}
During the ongoing pre-concept phase $(2014-2020)$ for a possible future European DEMOnstration Fusion Power Plant (DEMO) the activities within EUROfusion WP HCD EC Gyrotron R\&D and Advanced Developments are focusing on options for near-term solutions, and, at the same time, on long-term even more advanced options. The near-term target for DEMO is to realize pulsed operation. According to the current baseline it will probably use an EC system operating at $170 \mathrm{GHz}$ and $204 \mathrm{GHz}$ is being assessed, whereas the long-term target aims for steady-state operation and frequencies for current drive up to $240 \mathrm{GHz}$. Common targets for both are an RF output power per unit of significantly above $1 \mathrm{MW}$ (target: $2 \mathrm{MW}$ ) and a total gyrotron efficiency of significantly higher than $60 \%$. Frequency steptunability and multi-purpose/multi-frequency operation have to be considered. Those targets shall be achieved by considering the coaxial-cavity gyrotron technology and advanced technologies for key components (e.g. CVD diamond-disk Brewster angle window). Advanced simulation and test tools are complementing the research and developments. Gyrotron development is additionally supported by a significant investment into a new multi-megawatt long-pulse gyrotron test stand which is under final installation at KIT currently.
\end{abstract}

\section{Introduction}

In Europe, coordinated by the EUROfusion program $[1,2]$ and within the EUROfusion Work Package Heating and Current Drive (WP HCD), the research and development is ongoing to find a suitable near-term solution for an Electron Cyclotron Heating and Current Drive (EC H\&CD) system of a possible future European DEMOnstration Fusion Power Plant (DEMO). Start of operation is planned to be by 2050 [3]. The EC heating system should consider a minimum of $50 \mathrm{MW}$ of heating power. In parallel, long-term, even more advanced options towards a real Fusion Power Plant (FPP) operating at steady state are under investigation. The timeframe during $2014-2020$ is called the pre-concept phase of EU DEMO.

Within the WP HCD EC project a major focus is put on the development of a suitable high-power fusion gyrotron. Considering the baseline 2017 of EU DEMO, that gyrotron will have to operate at $170 \mathrm{GHz}$ for heating and $204 \mathrm{GHz}$ for localized plasma stabilization whereas the long-term target for a future FPP aims for frequencies up to $240 \mathrm{GHz}(238 \mathrm{GHz})$ [4]. For both systems, an RF power per tube of significantly more than 1 MW (target: $2 \mathrm{MW}$ ) and a total gyrotron efficiency of higher than $60 \%$ are assessed. RF beam steering into the plasma by frequency tuning might be an option. Therefore, the gyrotron must enable a frequency tuning in steps of around 2-3 GHz. A tuning bandwidth of approximately $\pm 10 \mathrm{GHz}$ is currently considered. Multipurpose operation at multiples of the $\lambda / 2$-resonance frequency of the RF gyrotron window, hence in leaps of about $30-40 \mathrm{GHz}$ (e.g. at 136/170/204/238 GHz) might be considered for different scenarios such as plasma start-up, heating and plasma instability mitigation.

At the start of the EUROfusion program, both the advanced coaxial-cavity gyrotron technology, and, as a possible fall back solution, the conventional hollowcavity gyrotron technology were under investigation [5]. The target was to achieve a fundamental understanding

*Corresponding author: john.jelonnek@kit.edu 
on the efficiency and final operation stability at nominal operating conditions and at different parameter variations. A design strategy was developed that did help to find the optimum operating mode for the two different cavity topologies. Operating scenarios close to $2 \mathrm{MW}$ for the coaxial-cavity technology and significantly above $1 \mathrm{MW}$ for the conventional cavity technology were found in the theoretical analyses considering realistic targets for the thermal wall loading and the electron beam quality [6,7]. In the theoretical analyses it was found that the coaxial-cavity technology will offer a significant better potential with regards to the performance. The decision was done to focus on the coaxial-cavity technology. Concerning that, an additional experimental investigation using the unique KIT modular gyrotron technology at longer pulses (pulse lengths up to $100 \mathrm{~ms}$ (first stage) and up to $1 \mathrm{~s}$ (final stage)) is in preparation. It shall finally demonstrate the operation capabilities. In frame of frequency steptunable RF sources, significant investments in advanced CVD diamond-disk Brewster-angle window technology are considered. Different promising concepts for multistage depressed collectors (MDCs) are under investigation. The new KIT teststand FULGOR is under final construction. It will support the long-pulse and $\mathrm{CW}$ tests of future DEMO gyrotrons operating up to $4 \mathrm{MW}$ output power using dual-beam output $(2 \times 2 \mathrm{MW})$.

\section{TOWARDS A LONG-PULSE COAXIAL CAVITY PRE-PROTOTYPE}

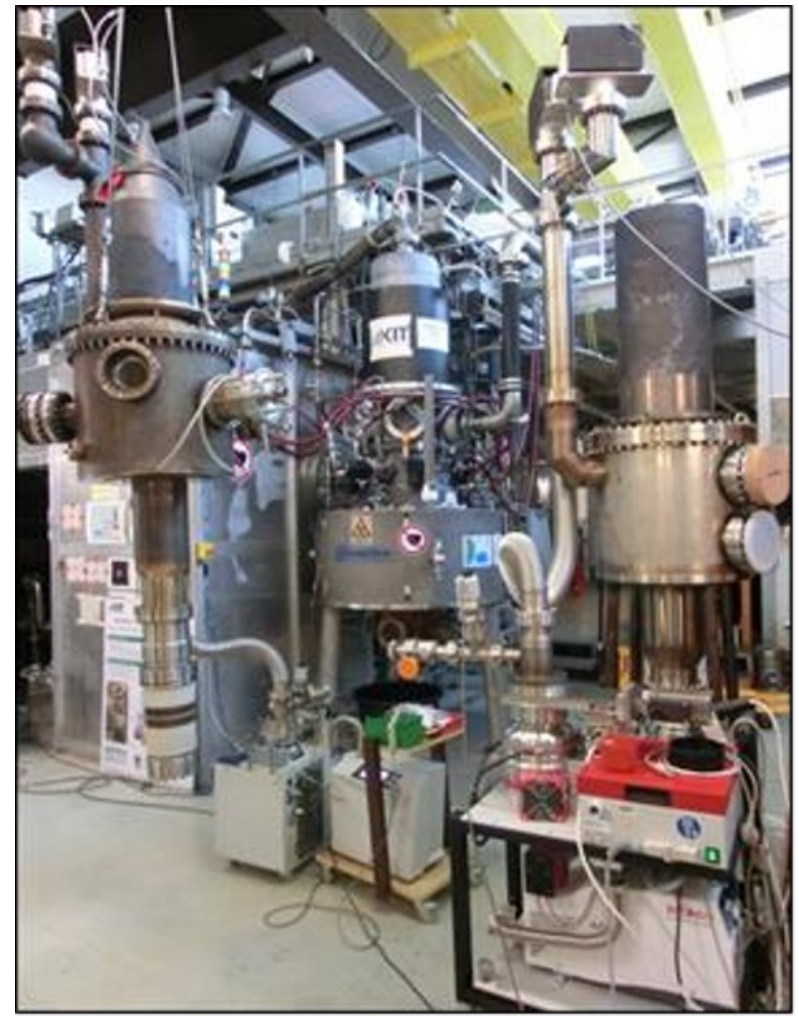

Fig. 1. From left-to-right: The $170 \mathrm{GHz} 2 \mathrm{MW}$ short-pulse (ms) coaxial-cavity pre-prototype; the W7-X $140 \mathrm{GHz} 1 \mathrm{MW}$ $\mathrm{CW}$ series gyrotron; the ITER $170 \mathrm{GHz} 1 \mathrm{MW}$ short-pulse (ms) pre-prototype at the gyrotron test stand at Karlsruhe.
Figure 1 shows the two EU short-pulse pre-prototypes, the $170 \mathrm{GHz} 2 \mathrm{MW}$ short-pulse (ms) $\mathrm{TE}_{34,19}$-mode coaxial-cavity tube (left) and the ITER $1 \mathrm{MW} \mathrm{TE}_{32,9-}$ mode short-pulse (ms) tube (right). In fig. 1 both tubes are surrounding the $\mathrm{W} 7-\mathrm{X} 140 \mathrm{GHz} 1 \mathrm{MW} \mathrm{CW}$ series gyrotron mounted in the super-conducting magnet. The coaxial-cavity pre-prototype delivered already an RF output power of above $2.2 \mathrm{MW}$ at short pulses, reliably in several experimental campaigns (ms-range) [8]. The verification at long pulses up to $1 \mathrm{~s}$ will be the final proof of concept and will demonstrate the applicability of the coaxial-cavity technology. The $1 \mathrm{~s}$ pulse length is considered to be the necessary time to achieve an operation close to steady state with regards to thermal expansion, beam neutralization and beam stability. The unique modularity of the KIT short-pulse pre-prototype shall be kept under all circumstances. The modular short-pulse pre-prototype is being upgraded in two steps. The target of the first step is to allow a reliable operation at $2 \mathrm{MW}$ at pulse lengths up to $100 \mathrm{~ms}[9,10]$. Figure 2 shows the finally upgraded pre-prototype before installation into the super-conducting magnet at KIT.
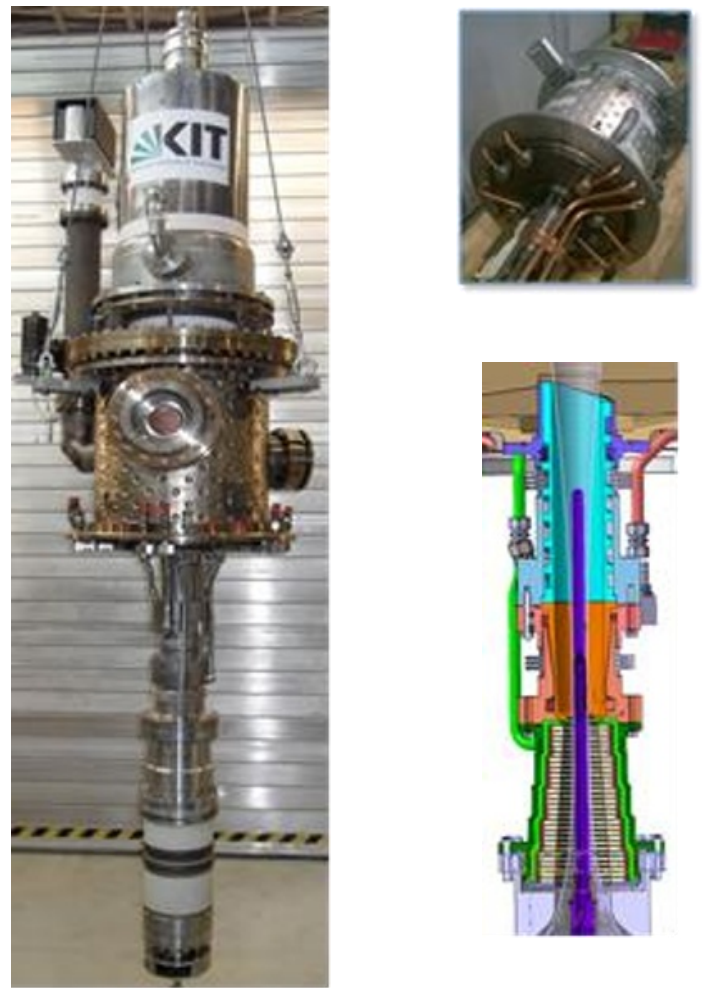

Fig. 2. Photo of the upgraded KIT 2 MW coaxial-cavity preprototype to operate at pulse lengths up to $100 \mathrm{~ms}$ (left). Upgrade of the mirror box showing the cooling system (upper right). Sketch of the key components which have been upgraded with advanced cooling systems (lower right).

This first stage includes the equipment of all thermally loaded key components of the short-pulse pre-prototype, namely beam tunnel, cavity, launcher and mirrors with advanced cooling structures. For the cavity and collector cooling different concepts are under investigation. The final second development step will include the introduction of a long-pulse collector and a CVD diamond disk RF output window. In [11] the latest 
developments and plans of the coaxial-cavity development are explained in more detail.

\section{TOWARDS ADVANCED GYROTRON KEY COMPONENTS}

The targets for a total gyrotron efficiency of higher than $60 \%$ and the required frequency step-tunability are calling for the development of advanced key components within the EUROfusion program. The reduction of the manufacturing complexity and costs are additional drivers. In the following sections, four areas are briefly described which had been in the focus: new and advanced gun (MIG) designs, advanced cooling concepts for cavity and collector, novel concepts for multi-stage depressed collectors and the broadband CVD diamond disk Brewster-angle window.

\subsection{Towards an advanced MIG design}

Within the European gyrotron development program the design of the magnetron injection gun (MIG) is one of the major focus areas. The helical electron beam determines the proper excitation of the operating mode in the cavity, the maximum generated microwave power, and, finally, the gyrotron efficiency. Trapped electrons, manufacturing tolerances, surface roughness of the emitter ring, temperature inhomogeneity of the emitter surface and the electron beam neutralization are influencing the electron beam properties. [12] presents the research status on the influence of some of those factors on the electron beam. Several novelties developed are listed, e.g. detailed design criteria for the suppression of trapped electrons are shown. An emitter ring to minimize the influence of the manufacturing tolerances and edge effects on the beam quality is proposed. It bases on the finding, that the electron beam reacts very sensitive to the alignment of the emitter ring. A minor radial displacement due to manufacturing tolerances $(\sim 80 \mu \mathrm{m})$ is significantly influencing the beam properties already. A possible solution to this is the introduction of anti-emissive regions on the two end rims of the emitter ring [13]. A major step towards even higher output power and frequency will be an Inverse Magnetron Injection Gun (IMIG) as proposed in [14]. This novel IMIG is already manufactured for the KIT 2 MW coaxial-cavity gyrotron and waiting for tests. It is estimated that this type of inverse MIG will lead to more compact sizes and even more stable operation at even higher output power. Due to the triode configuration, the IMIG, originally designed for gyrotron operation at $170 \mathrm{GHz}$ will also properly work at a frequency of 204 $\mathrm{GHz}$. Because of the larger emitter radius, the gyrotron can be operated at a larger electron beam current and therefore at higher RF output power. The already performed inspection of the manufactured IMIG showed excellent surface conditions and small tolerances, which promises a homogenous electric field distribution in the emitter region and a high quality of the hollow electron beam. The placement of the emitter has been checked by using a precise optical laser measurement. Furthermore, proper welding and solder joints result in an excellent leakage rate $<10^{-12} \mathrm{mbar} / \mathrm{s}$. Figure 3 shows the two manufactured MIGs. The left part shows the MIG, produced by Thales, including an advanced emitter ring with non-emissive coatings. The right picture shows the inverse MIG, manufactured by KIT.

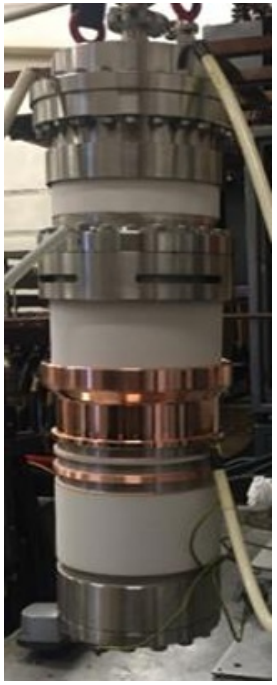

THALES

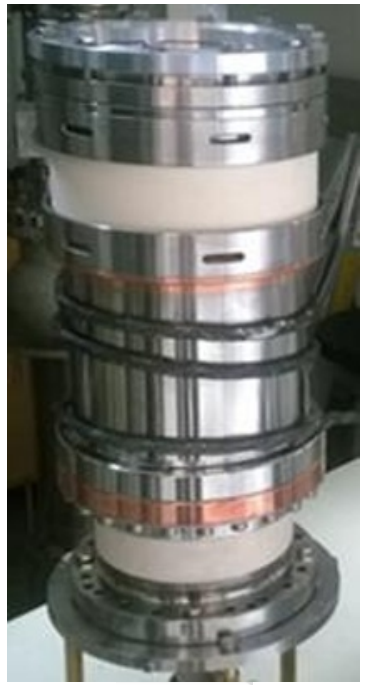

N $\mathrm{K}$ IT
Fig. 3. Advanced coaxial MIGs prepared for tests with the KIT $2 \mathrm{MW} 170 \mathrm{GHz}$ coaxial-cavity gyrotron. Left: MIG including an advanced emitter ring with non-emissive coating; right: Inverse MIG with reversed configuration of emitter ring and anode.

\subsection{Towards operation of a coaxial-cavity gyrotron at $170 \mathrm{GHz} / 204 \mathrm{GHz} / 238 \mathrm{GHz}$}

In [6] the theoretical performance capability of a coaxialcavity gyrotron operating at multiples of the $\lambda / 2$ resonance frequency of the RF output window at up to $238 \mathrm{GHz}$ was investigated by systematic theoretical analyses. It was shown that a coaxial-cavity gyrotron operating in a very high-order mode is capable to produce $2 \mathrm{MW}$ RF output power. On the other hand, it would be much simpler, if one could operate a modified version of the existing $2 \mathrm{MW} 170 \mathrm{GHz} \mathrm{TE}_{34,19}$-mode pre-prototype at $204 \mathrm{GHz}$ and at $238 \mathrm{GHz}$ even. In [15] it is shown by simulations that the existing KIT $\mathrm{TE}_{34,19-}$ mode coaxial-cavity pre-prototype gyrotron is capable to operate in the new KIT FULGOR gyrotron test stand using a $10.5 \mathrm{~T}$ super-conducting magnet if the gyrotron construction will be slightly adapted. The modified gyrotron will be capable to operate as a multi-purpose / multi-frequency device. Without any other modifications it is expected that the gyrotron will deliver $1.7 \mathrm{MW}$ $(2.5 \mathrm{MW})$ at $204 \mathrm{GHz}(170 \mathrm{GHz})$. The interaction efficiency is expected to be $31 \%$ (37\%). Another modification of the cavity would raise the RF output power by $\sim 0.4 \mathrm{MW}$. The interaction efficiency will increase by $1.3 \%$ percent points at $204 \mathrm{GHz}$. 


\subsection{Towards a multi-stage depressed collector}

Single-stage depressed collectors achieve collector efficiencies of about $60 \%$ and are successfully used in high-power fusion gyrotrons, increasing the overall efficiency to above $50 \%$. The further increase of the overall gyrotron efficiency requires an efficient multistage depressed collector (MDC) system. For the same reason, e.g. space-TWTs are operating with MDCs very successfully. However, the design of a MDC for a high-power gyrotron operating at a magnetic field of several Tesla and a large hollow electron beam is not that trivial. Additionally, it requires the effective suppression of secondary electrons. A possible design is the so-called $\mathrm{E} \times \mathrm{B}$ drift concept as shown in fig. 4 .

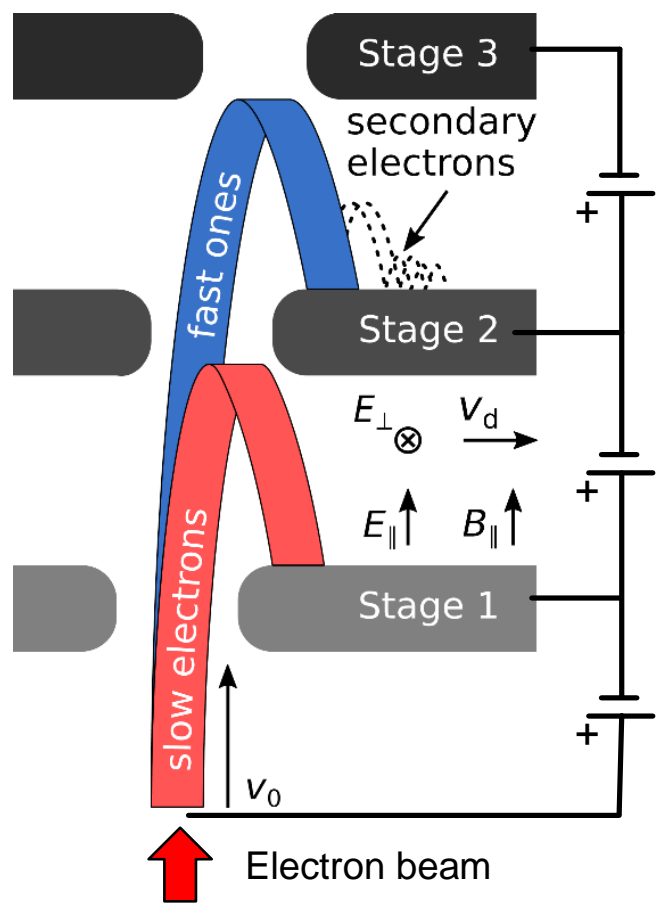

Fig. 4. Design principle of the $\mathrm{E} \times \mathrm{B}$ drift MDC concept.

Several theoretical design approaches based on the $\mathrm{E} \times \mathrm{B}$ drift have been recently published [16-20]. In [16] the $\mathrm{E} \times \mathrm{B}$ drift concept was proposed because of the efficient sorting of the magnetically confined gyrotron electron beam to the different electrodes. In that first investigation, a theoretical design was proposed for the demonstration of the $\mathrm{E} \times \mathrm{B}$ drift concept also. The collector efficiency was estimated to be of the order of $91 \%$. However, in that study an ideal situation with an infinite number of electrodes was considered due to limitations of the simulation tool used at that time. Figure 5 shows a so-called helical MDC which bases on the $\mathrm{E} \times \mathrm{B}$ concept as earlier proposed in [20]. In [21], advanced concepts of this type of MDC are numerically investigated with a full three dimensional simulation tool. MDCs with two, three and four stages have been optimized for a spent beam of a high power gyrotron. High efficiency has been demonstrated for a variety of realistic spent beam energy distributions with negligible reflected current.

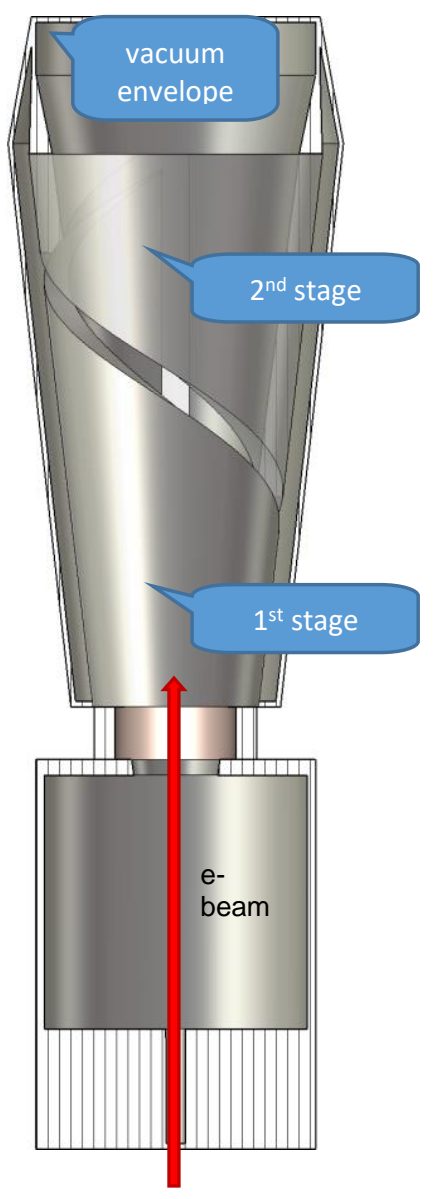

Fig. 5. Principle of a 2-stage collector with helical electrodes making use of the ExB drift concept according to [20].

\subsection{Towards a broadband CVD diamond disk Brewster-angle window}

It is assumed that future high-power transmission lines for fusion power plants will have to be capable to handle $2 \mathrm{MW}$ of RF power at minimum. Hence, it is assumed that the waveguide diameter will be minimum $63.5 \mathrm{~mm}$ as originally foreseen for ITER. Figure 6 shows a sketch of such a waveguide with a CVD diamond Brewsterangle window. It follows that the large diameter of such a Brewster-angle window will have to be minimum $180 \mathrm{~mm}$. State of the art is a maximum diameter of $140 \mathrm{~mm}$.

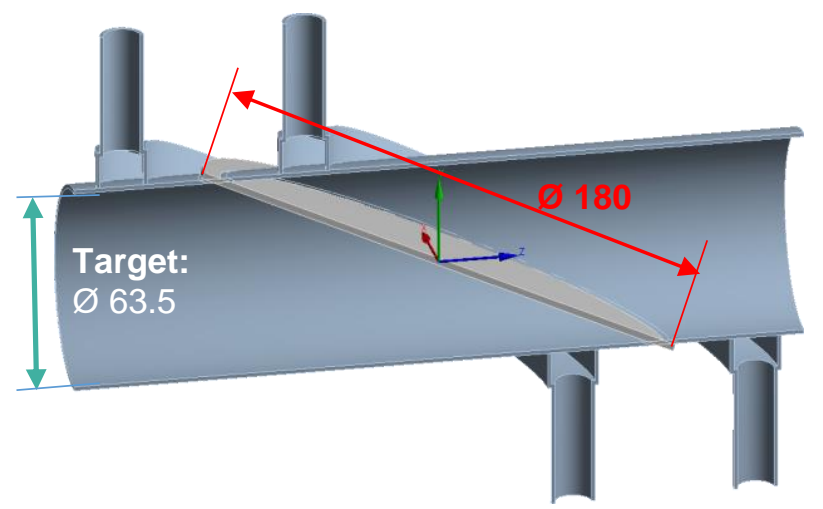

Fig. 6. Corrugated $\mathrm{HE}_{11}$ waveguide with future large diameter CVD diamond disk Brewster-angle window. 
In 2017, at the industrial partner Diamond Materials, Freiburg, Germany [22], first attempts of directly growing a diamond disk with a large diameter of $180 \mathrm{~mm}$ using the microwave plasma chemical vapour deposition (CVD) process were done. These attempts resulted from the fact that the previous attempt of producing a large Brewster-angle diamond disk by joining diamond fragments using the hot filament method to overgrow the joint gap with diamond raised several drawbacks.

With the aim of growing diamond disks of $180 \mathrm{~mm}$ diameter, a development approach having several steps is applied. In this frame, up to November 2017, two growth experiments for parameter optimization have been successfully carried out. Each growth experiment run for approximately 350 hours resulting in rather homogeneous diamond wafers of good optical quality with a thickness of about 300 to $450 \mu \mathrm{m}$. Due to the very small thickness, the two wafers did not remain in one piece after dissolving the silicon substrate. Nevertheless, it was possible already to cut a $39 \mathrm{~mm}$ diameter disk to be used for loss tangent measurements at KIT. In 2018, growing experiments will be carried out to produce, first, a disk with a thickness of about $700 \mu \mathrm{m}$ and then a disk of $2 \mathrm{~mm}$ thickness which represents the final target.

\subsection{Towards smart control of gyrotrons}

In future, smart control systems shall allow higher output powers of gyrotrons by reducing the necessary beam voltage safety margins [23]. Wendelstein 7-X (W7-X) uses ten $140 \mathrm{GHz}$ gyrotrons for electron cyclotron resonance heating $(\mathrm{ECRH})$. Approaching the practical maximum output power limit causes the excitation of unwanted parasitic and satellite modes which often results in a loss of the nominal operating mode. Therefore, the gyrotrons are operated with individual safety margins at reduced output powers to prevent a possible mode loss during operation. The power of those unwanted parasitic and satellite modes is converted to stray radiation. That radiation can be used as a precursor for mode loss indicating a potentially unstable operation state of the gyrotron. A dedicated diagnostic and control system could help to mitigate mode losses and to reduce necessary safety margins in operation. It would increase the maximum useable output power. In [24] the feasibility of a fast gyrotron controller with a real-time satellite mode activity feedback as a mode-loss precursor and an automated mode recovery is demonstrated.

\section{FULGOR}

KIT is currently funding a significant extension of its existing gyrotron test stand. That new test stand named FULGOR will allow the test of gyrotrons with up to $2 \times 2$ MW RF output power with dual-beam output [25].

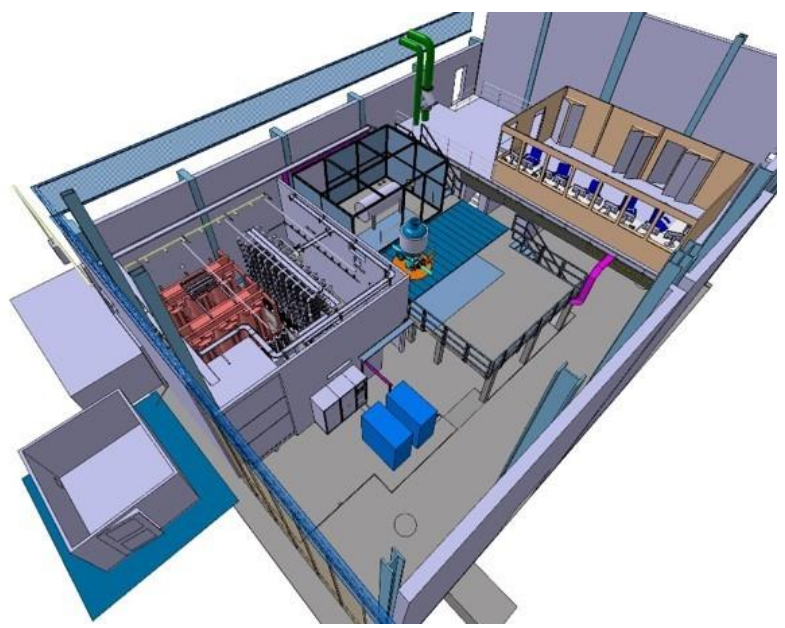

Fig. 8. 3D sketch of FULGOR, the KIT gyrotron test stand.

The installation of the main part, the $10 \mathrm{MW} \mathrm{CW}$ high voltage DC power supply (HVDCPS) has been completed in spring of 2018 by Ampegon, Turgi, Switzerland. The HVDCPS consists of an all solid-state modulator which is also capable of supplying gyrotrons with multi-stage depressed collector. While the effort for the development of the MDC is significant, the additional effort on the power supply is moderate. It is accompanied with a reduced noise level compared to a conventional pulse step modulator (PSM). This new PSM, which is the world largest today, consists of a cascade of so-called enhanced-PSM (EPSM) modules which provides a voltage of up to $90 \mathrm{kV}$. It can be tapped into at each intermediate connection point, thus giving considerable flexibility in selecting the voltage potential for each of the collector segments of a MDC. An additional option allows for $130 \mathrm{kV} / 120 \mathrm{~A}$ nondepressed short pulse operation (all collector segments grounded) up to $5 \mathrm{~ms}$ every $2 \mathrm{~s}$. The second major installation, will be a $10.5 \mathrm{~T}$ super-conducting magnet. The Call for Tender was launched in May 2017. After receiving competitive offers from three different companies and evaluating the proposals, the placement of the order was performed in November 2017. This SCM which is partially funded by EUROfusion will fulfill all requested specifications; the delivery is scheduled for the mid of 2019. It will provide a maximum magnetic field of $10.5 \mathrm{~T}$ at the center of the gyrotron cavity and will have a warm bore hole diameter of $261 \mathrm{~mm}$. The allowed distance from the emitter to the cavity will be $400 \mathrm{~mm}$. A dipole coil system for alignment of the electron beam will consist of 12 coils operating at full field with a possible shift of the beam at the cavity of $0.5 \mathrm{~mm}$. The magnet will have a cryogenfree cooling system with two cooling heads. It does not contain a liquid-He-reservoir.

\section{CONCLUSION}

Within the EUROfusion Work Package Heating and Current Drive (WP HCD EC), the research and development is ongoing to find a suitable near-term solution for an Electron Cyclotron Heating and Current Drive system for the future EU DEMO. The 
development of a suitable high-power fusion gyrotron is one of the main research items. The coaxial-cavity gyrotron technology was chosen as the technology for future multi-megawatt gyrotrons operating at multiple frequencies. The existing KIT $170 \mathrm{GHz}$ short-pulse preprototype has been upgraded to operate at longer pulses. It is under test currently. Using the new FULGOR test stand and the new $10.5 \mathrm{~T}$ magnet a modified version will be prepared to run at frequencies above $200 \mathrm{GHz}$. The gyrotron development is accompanied by the research on advanced key components, such as MIG, MDC and broadband RF window.

This work has been carried out within the framework of the EUROfusion Consortium and has received funding from the Euratom research and training programme 2014-2018 under grant agreement No 633053. The views and opinions expressed herein do not necessarily reflect those of the European Commission. A part of this work was carried out using the HELIOS supercomputer system at Computational Simulation Centre of International Fusion Energy Research Centre (IFERC-CSC), Aomori, Japan, under the Broader Approach collaboration between Euratom and Japan, implemented by Fusion for Energy and QST.

\section{REFERENCES}

1. EUROfusion, https://www.euro-fusion.org/, (2018)

2. G. Federici, C. Bachmann, L. Barucca, W. Biel, L. Boccaccini, R. Brown, C. Bustreo, S. Ciattaglia, F. Cismondi, M. Coleman, V. Corato, C. Day, E. Diegele, U. Fischer, T. Franke, C. Gliss, A. Ibarra, R. Kembleton, A. Loving, F. Maviglia, B. Meszaros, G. Pintsuk, N. Taylor, M. Q. Tran, C. Vorpahl, R. Wenninger, J. H. You, ISFNT13, (2017)

3. G. Federici, the PPPT PMU and Project Teams, http://www.firefusionpower.org/NAS EU DEMO Federici.pdf, (2018)

4. J. Jelonnek, G. Aiello, S. Alberti, K. Avramidis, F. Braunmueller, A. Bruschi, J. Chelis, J. Franck, T. Franke, G. Gantenbein, S. Garavaglia, G. Granucci, G. Grossetti, S. Illy, Z. C. Ioannidis, J. Jin, P. Kalaria, G. P. Latsas, I. Gr. Pagonakis, T. Rzesnicki, S. Ruess, T. Scherer, M. Schmid, D. Strauss, C. Wu, I. Tigelis, M. Thumm, M. Q. Tran, Fus. Eng. Des., 123, (2017)

5. J. Jelonnek, G. Aiello, S. Alberti, K. A. Avramidis, F. Braunmüller, J. Franck, T. Franke, G. Gantenbein, S. Garavaglia, G. Granucci, G. Grossetti, S. Illy, Z. Ioannidis, J. Jin, P. Kalaria, I. Gr. Pagonakis, T. Rzesnicki, S. Ruess, T. Scherer, D. Strauss, M. Thumm, I. Tigelis, M. Q. Tran, C. Wu, J. Zhang, EC-19 workshop, (2016)

6. J. Franck, KIT Scientific Publishing, http://dx.doi.org/10.5445/KSP/1000068000 (2017)

7. P. Kalaria, KIT Scientific Publishing, http://dx.doi.org/10.5445/KSP/1000073581 (2018)
8. T. Rzesnicki, B. Piosczyk, S. Kern, S. Illy, J Jin, A. Samartsev, A. Schlaich, M. Thumm, IEEE Trans. Plasma Sci., 38, 6 (2010)

9. S. Ruess, G. Gantenbein, A. Heinzel, S. Illy, I. Gr. Pagonakis, T. Rzesnicki, M. Thumm, J. Weggen, A. Weisenburger, J. Jelonnek, EPJ Web of Conferences 149, 04015 (2017)

10. S. Ruess, K. A. Avramidis, M. Fuchs, G. Gantenbein, S. Illy, P. C. Kalaria, T. Kobarg, I. Gr. Pagonakis, T. Rzesnicki, M. Thumm, J. Weggen, J. Jelonnek, $47^{\text {th }}$ EUMC, (2017)

11. S. Illy, EC-20 workshop, (2018)

12. I. Gr. Pagonakis, S. Alberti, K. Avramidis, F. Legrand, G. Gantenbein, J. Genoud, J.-P. Hogge, S. Illy, Z. Ioanidis1, P. Kalaria, B. Piosczyk, S. Ruess, T. Ruess, T. Rzesnicki, M. Thumm, I. Vomvoridis, J. Jelonnek, EC-20 workshop, (2018)

13. I. Gr. Pagonakis, S. Illy, M. Thumm, Phys. Plasmas, 23, 83103 (2016)

14. S. Ruess, I. Gr. Pagonakis, G. Gantenbein, S. Illy, T. Kobarg, T. Rzesnicki, M. Thumm, J. Weggen, J. Jelonnek, IEEE Trans. Electron Devices, 63, 5 (2016)

15. T. Ruess, K. Avramidis, G. Gantenbein, S. Illy, Z. Ioannidis, J. Jin, P. Kalaria, I. Gr. Pagonakis, S. Ruess, T. Rzesnicki, M. Thumm, J. Jelonnek, EC20 workshop, (2018)

16. I. Gr. Pagonakis, J.-P. Hogge, S. Alberti, K. Avramidis, J. Vomvoridis, IEEE Trans. Plasma Science, 36, 2 (2008)

17. O. Louksha, P. A. Trofimov, Tech. Phys. Lett. 41, 9 (2015)

18. I. Pagonakis, C. Wu, S. Illy, J. Jelonnek, Phys. Plasmas, 23, 4 (2016)

19. C. Wu, I. Gr. Pagonakis, G. Gantenbein, S. Illy, M. Thumm, J. Jelonnek, Phys. Plasmas, 24, 4 (2017)

20. C. $\mathrm{Wu}, \quad$ I. Gr. Pagonakis, K. Avramidis, G. Gantenbein, S. Illy, M. Thumm, J. Jelonnek, Phys. Plasmas, 25, 033108 (2018)

21. B. Ell, I. Gr. Pagonakis, C. Wu, J. Jelonnek, EC-20 workshop, (2018)

22. Diamond Materials GmbH, 79108 Freiburg, http://www.diamond-materials.com/DE/index.htm

23. F. Wilde, H. P. Laqua, S. Marsen, T. Stange, K. Avramidis, G. Gantenbein, J. Jelonnek, S. Illy, I. Gr. Pagonakis, M. Thumm, Proc. IVEC, (2017)

24. F. Wilde, K. Avramidis, G. Gantenbein, S. Illy, J. Jelonnek, H. P. Laqua, S.Marsen, J. W. Oosterbeek, I. Gr. Pagonakis, T. Stange, M. Thumm, R. Wolf, the W7-X team, Proc. IVEC, (2017)

25. M. Schmid, M. Bader, T. Bourgeois, A. Epp, G. Gantenbein, M. Iten, J. Jelonnek, T. Kobarg, W. Leonhardt, D. Mellein, T. Rzesnicki, Fus. Eng. Des., 123, (2017) 